Why stocks with the worst expected future price development are the best investment:

A psychological study of financial analysts' reports

Supervisor: Henry Montgomery and Gustaf Törngren, PSYKOLOGI III,

VETENSKAPLIG UNDERSÖKNING, 15 HP, HT 2010 STOCKHOLMS UNIVERSITET
PSYKOLOGISKA INSTITUTIONEN 


\title{
WHY STOCKS WITH THE WORST EXPECTED FUTURE PRICE DEVELOPMENT ARE THE BEST INVESTMENT: A PSYCHOLOGICAL STUDY OF FINANCIAL ANALYSTS' REPORTS
}

\section{Marcus Carleson}

\begin{abstract}
Financial analysts produce investment reports containing two outputs: one recommendation and one target price. This study compared and contrasted the investment value of the two by employing recognised decision making theories. For this purpose 89.814 analyst reports, or 4.956 consensus reports, based on US data (S\&P 500) was employed to form recommendation and target price portfolios with a holding period of 1, 3, 6, 12 and 24 months. The findings indicated a negative relationship between the two variables. Seeking to make profits, it therefore seems as if an investor should buy stocks with the most favourable recommendations but, surprisingly, also stocks with the least optimistic target prices. The explanation for the anomaly was primarily sought in the compatibility principle, preference reversals, configural weight theory or temporal distance theory and possibly in the analysts' evasion of regret and protection of their reputation and employment.
\end{abstract}

Financial analysts are an occupational group employed by mutual funds, pension funds, hedge funds, banks and insurance companies. Their main task is to evaluate the future prospects of a number of companies, a fairly difficult task bearing in mind the huge amount of parameters they have to take into consideration. Ultimately, these parameters help the analysts conduct a valuation of the company, which in combination with other available information constitute the foundation for the target price. Being a monetary measure of future performance, the target price is an estimation of the "true" value of a share, usually with a 12 month perspective. Depending on the target price's magnitude in relation to the current share price, the recommendation whether to "buy", "hold" or "sell" the share is set. These reports are utilized by the analysts' employer or sold to other companies who seek to make the most out of their investments. However, whether or not the target price and recommendation should be analogous in investment value is from a decision-making perspective an open question.

Whether or not analysts' have forecasting abilities has been debated for almost a century, starting with Cowles (1933) well-known study "Can stock market forecasters forecast?". In line with his critical view on analysts' skills, Desai and Jain (1995) analysed 24 years of Barron's Roundtable recommendations and concluded that investors do not benefit from analysts' advice. In contrast to these sceptical papers, a majority of the findings in the field hold the opposite view, namely that those investing in accordance with analysts' recommendations earn significant abnormal returns (returns higher than what could be expected given the exposure to risk a certain investment is associated with). For instance, Dimson and March (1984) reported that analysts' forecasting abilities, as measured by their target prices, is as accurate for the following month as 12 months into the future. Hence, by investing accordingly, an investor could make profits. These findings were given further credibility as many 
researchers such as Elton, Gruber and Grossman (1986) and Stickel (1995) applied different methodologies but made the same discoveries. Stickel (1995) found buy recommendations to be associated with $1.16 \%$ price increase and sell recommendations with $-1.28 \%$ price decrease, over 11 days centred on the date of the recommendation. Another view on the matter, first introduced by Grossman and Stiglitz (1980), was that analysts do have stocks-selecting skills, but due to the transaction costs associated with the required heavy trading, they are unexploitable. Barber, Lehavy, McNichols and Trueman (2001) authored another of these studies. Excluding trading costs, they found analyst recommendations to yield gross return greater than $4 \%$. However, when transaction costs were considered, none of their evaluated strategies generated abnormal net returns significantly above zero.

Although financial markets have been researched for as long as they have existed, the psychological aspect of them was not academically considered until Selden's 1912 paper "Psychology of the stock market". Ever since, the intensity of the research in the cross section of finance and psychology has intensified, and today the psychological aspect of financial markets has become an increasingly legitimate explanation for many of the observed anomalies. In the epicentre of this research stand financial analysts and their presumed forecasting abilities, examined from a wide range of perspectives. Hong, Kubik and Solomon (2000) reported the importance of analysts' age as they found older analysts to be more accurate than younger ones, whereas Clement and Tse (2005) emphasised how analysts' previous accuracy and forecast frequency positively affected their forecasting abilities. Others, such as Welch (2000) concentrated on how one analyst's judgement might be affected by herding behaviour. He found that analysts are willing to sacrifice some accuracy in order to stay close to the opinion of other analysts, following the same stock. Pratt (1993) and Asquith, Mikhail and Au (2005) agreed with Welch's (2000) findings. They also expanded the explanation for analysts limited forecasting abilities to include their concerns over personal compensation, ultimately affecting and compromising their judgement.

Evidently, several studies document analysts' limited forecasting accuracy and an increasing number of studies try to link analysts' behaviour to psychological mechanisms, herding in particular. Most studies have, however, been conducted by observing analysts' recommendations, whereas target prices, and especially the relation between the two, has been scarcely investigated. Being an exception, Kanne and Kreutzmann (2008), reported that the return of a stock follow the change in target price and is particularly high when the change in target price coincides with a recommendation change in the same direction. Their explanation for the findings was that analysts in some situations are either unaware of the information in their own target price forecasts or use target price changes to signal private information to the market if outside pressure prevents them from changing the recommendation. Although Kanne and Kreutzmann's (2008) paper was a significant contribution to the field, they only considered changes in target prices and recommendations. More importantly, they failed to consider the main psychological mechanisms driving analysts decision-making. After all, analysts are humans, and for that reason decision-making theories from the area of psychology should be a valuable tool for predicting the nature of the relationship between analysts' recommendations and target prices. 
The main psychological theories of relevance for the present study can be divided into two groups: The consistency groups and the inconsistency group. The first implies that recommendations and target prices should be consistent with each other and includes two theories. The theory of cognitive dissonance, as proposed by Festinger, Riecken and Schachter (1956) asserts that people strive to be consistent in their values and beliefs, and in case they are not, that would produce an unpleasant state of mind called cognitive dissonance. Hence, if the analysts values the company higher than the share is trading for, then he or she naturally would link that to the recommendation "buy" or perhaps even "strong buy", but certainly not "sell". The main motivational factor in this theory is that a sell recommendation would produce cognitive dissonance. The other theory standard analysis of choice, assumes procedure invariance, which entails that the same preference order should hold no matter the assessment procedure (Edwards \& Newman, 1982; Keeney \& Raiffa, 1976). Hence, if an analyst estimates a stock to be undervalued, then regardless if he or she estimates its target price or recommendation; they should both express the same opinion. Consequently, for two different reasons, these theories would yield the predication that analyst recommendations and target prices are equivalent and comparable.

Even though analysts' consistency is both expected and corresponds to common sense, there are psychological research findings as well as theories predicting the opposite. This is named as the inconsistency group. Being one of the earlier contributions to it, Slovic and Lichtenstein (1968) found that depending on response type, people seemed to inverse their preferences. This caused scientists, such as Fischhoff, Slovic and Lichstenstein (1980), March (1978) and Shafer and Tversky (1985) to question if people really have well defined beliefs. In contrast to the theory of procedure invariance, they all reported the opposite: preferences seemed to rather be constructed in the actual process of choosing and might depend on a variety of parameters. One of the violations of procedure invariance, the choice-matching discrepancy, suggests that the weighting of option attributes is influenced by the method of elicitation. More specifically, it claims that alternative procedures highlight different aspects of the options, which in turn bring about different weighing of attributes as proposed by Birnbaum and Zimmermann's (1998) configural weight theory. One of the presented explanations for this weighing procedure is called the compatibility principle (Tversky, Sattah \& Slovic, 1988). The logic behind the theory is that the dimension emphasised in the task and the response primes the most attuned features of the stimulus. Put in this paper's context, this reasoning point out that the lack of procedure invariance could cause analysts to produce weakly linked recommendations and target prices. Moreover, it postulates that due to the fact that recommendations and target prices are expressed in different scales, it might cause analysts to weigh the information at hand differently depending on the type of response (target price or recommendation). Thereby they might be more influenced by variables expressed in monetary terms when setting the target price while being more influenced by variables expressed in evaluative terms when setting the recommendation. Both scale comparability and construal weight theory were demonstrated in a business-like situation by Slovic, Griffin and Tversky (1990). They conducted an experiment in which half of the participants were asked to predict the market value of 12 companies 1987 based on their market value 1986 and the other half were asked to estimate the same companies' rank as per their 1987 profits. As implied by comparability, each predictor was emphasised when the criterion was expressed on 
the same scale. More specifically, the weight of the 1986 market value was twice as high for those who predicted dollars than those who predicted the rank. This could also be the case for financial analysts in the present study.

Furthermore, Trope and Lieberman (2003) took another approach and developed the theory of temporal distance, which posits that the greater the temporal distance to a certain event, the more likely it is that this event will be represented in terms of abstract features. Events closer in time, on the other hand, are more likely to be associated with concrete and incidental details. In the present context, it is assumed that analysts' target prices are set with a 12 month perspective, but whether or not they in fact are, or if the recommendations have the same perspective is unknown. Consequently, this theory would predict recommendations and target prices to be equivalent in accordance with the consistency group, but only as long as they are set with the same temporal distance. If not, then this theory would predict that recommendations and target prices are loosely linked. However, people's decisions are not only reported to depend on the temporal distance or how the options are presented, weighted or framed, but also on the degree to which decision makers might regret the decision. Josephs, Larrick, Steele and Nisbett (1992) conducted a study concerned with regret in decisions and reported that the more a certain decision situation might damage self-esteem, the more the decision maker is drawn to risk-aversion. Zeelenberg, Beattie, van der Pligt and de Vries (1996) agreed with the importance of regret and expanded the explanation for it to also involve whether the decision maker would receive feedback after the decision on not. Consequently, it seems as if regret can be enforced by feedback and seriously damage self esteem. Therefore, people avoid these situations by playing safe. How this would turn out in the decision making situation analysts' face is unknown, but should certainly be considered an important aspect. One possibility is that they use their two tools, recommendations and target prices, to represent totally different scenarios to always be able to justify that they were somewhat right in order to avoid regret. To sum up the second camp, it can be divided into two categories. The first, consisting of configural weight theory, scale compatibility, preference reversals and temporal construal theory, using cognitive aspects to describe decision making. The second category on the other hand, includes regret theory and is therefore represented by more conscious mechanisms.

The purpose of this study was to compare and contrast the investment value of analysts' consensus recommendations and consensus target prices in the light of the above decision theories by forming portfolios based on the recommendations and target prices respectively. This was conducted by employing a database which comprised 89.814 analyst reports and 4.956 consensus reports with 2006 as the forecasting year.

\section{Method}

\section{Sample Selection}

The sample employed in this study originally contained all companies listed on S\&P 500 as per December $1^{\text {st }}, 2010$. S\&P 500 is an index maintained by Standard \& Poor's and includes the 500 largest companies, measured by their market value, listed on either NYSE Euronext or NASDAQ OMX in the US. It was introduced in 1923 and has ever since been a widely followed and monitored proxy for the US economy. The companies 
on the list are handpicked by a special committee with respect to some specific requirements. These requirements are: that they represent the US industries in a satisfactory way, that they have sufficient liquidity and that they are actively traded public US companies. Thus, by employing this data, I ensured that the companies were well known, frequently traded and, most importantly, that they had a reasonable amount of analyst coverage. All of these aspects were important for the validity of the present study, underpinning the decision to use this particular dataset.

The analysts target prices and recommendations used in this study were gathered from I/B/E/S (Institutional Brokers' Estimate System), which obtains its data from over 700 brokerage houses in a variety of sizes. The database was originally set up in 1976, and has today grown to contain data for 60,000 companies in 67 countries worldwide. Its data is very detailed and includes among other items, target prices, recommendations, the date they were issued, identifiers for the brokerage house issuing them and the analyst responsible for it. $\mathrm{I} / \mathrm{B} / \mathrm{E} / \mathrm{S}$ codes the brokerage houses ways of issuing recommendation, which may vary, by translating them into their own system consisting of numbers from 1 to 5 , where $5=$ strong sell, $4=$ sell, $3=$ hold, $2=$ buy and $1=$ strong buy. The main advantage with this database is that it is very comprehensive and provides high quality information which has gained academic recognition throughout several studies before this one.

The sample consisted of monthly data downloaded from CRSP (The Center for Research in Security Prices) from January $1^{\text {st }}, 2000$ to December $31^{\text {st }}, 2007$. The first five years (2000-2005) were the estimation period of the co-moment between the individual stocks and S\&P 500, 2005 was the actual measurement period and 20052007 was the evaluation period. See Figure 1. Hence, with respect to the above, I employed 12 months of data (2005) for 500 companies, or 6000 data points. However, after deducting 72 companies for which data was missing in CRSP and another 15 for which data was missing in $\mathrm{I} / \mathrm{B} / \mathrm{E} / \mathrm{S}, 413$ companies remained. This equalled 4.956 data points of consensus data or 89.814 individual analyst reports. For every data point, actual prices, consensus target prices and consensus recommendations were collected the last weekday of every month. If an analyst published more than one report for a certain company and month, the latest one was used.

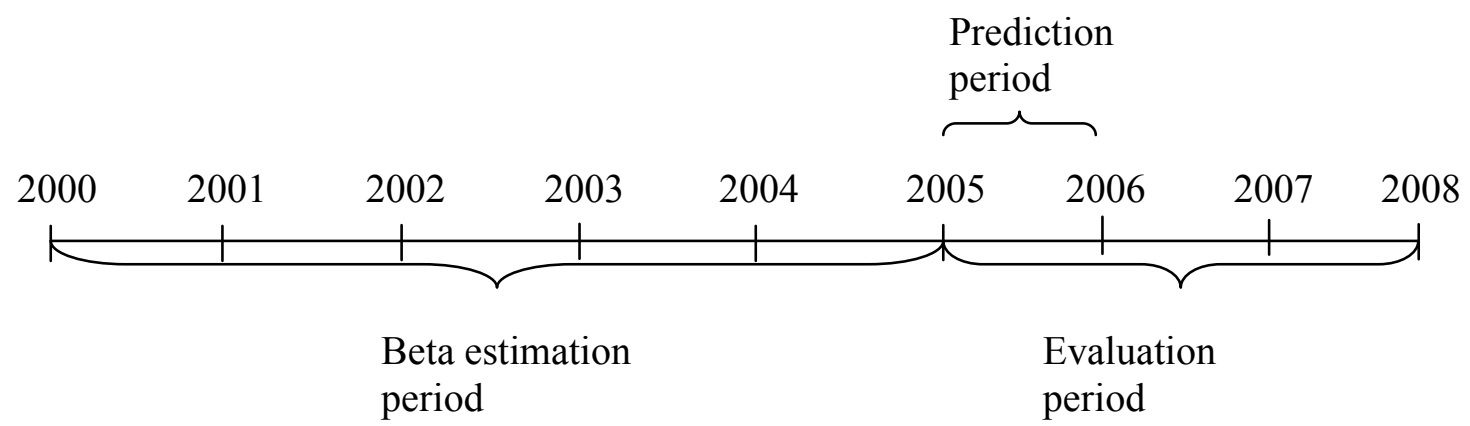

Figure 1. Beta estimation period refers to the period during which the risk level of each stock was estimated. Prediction period was where analysts' reports were gathered and 
portfolios formed based on some investment strategy. These portfolios were compared to actual stock returns during the estimation period, 2005, 2006 throughout 2007.

Procedure

Portfolio formation. To evaluate if there was any difference in investment value between analysts' recommendations and target prices, I formed portfolios the first day every month based on consensus recommendations and target prices from the previous month. Each portfolio was formed with respect to some unique investment criteria and five different holding periods were used: 1, 3, 6, 12 and 24 months. This was to shed light on which time horizon analysts' advice paid off the most. Whereas a recommendation is a standardised measure, the target price needed to be standardised in order to compare stocks trading on different price levels with each other. This was accomplished by forming the new variable Adjusted Target Price (ATP):

$$
A T P_{i, t-1}=\frac{T \arg \text { et } \operatorname{Pr} i c e_{i, t-1}}{\operatorname{Pr} \text { ice }_{i, t-1}}
$$

where TargetPrice $\mathrm{e}_{\mathrm{i}, \mathrm{t}-1}$ refers to the consensus target price for stock $i$ set during time $\mathrm{t}-1$ for the coming month and Price $\mathrm{e}_{\mathrm{i}, \mathrm{t}-\mathrm{i}}$ is the average stock price for stock $i$ during time $\mathrm{t}-1$. ATP is thus a coefficient which relates analysts' target prices to the actual price and a value higher than 1 should indicate that the analysts' believe the stock is undervalued whereas a value lower than 1 should indicate the opposite. After having created two measures upon which I could distinguish between the stocks, I defined four recommendation based portfolios and four ATP based portfolios. See table 1.

Table 1. Recommendation- and ATP portfolio classifications.

\begin{tabular}{llll}
\hline $\begin{array}{l}\text { Recommendation } \\
\text { Portfolio }\end{array}$ & Criteria & $\begin{array}{l}\text { ATP } \\
\text { Portfolio }\end{array}$ & Criteria \\
\hline $1 \mathrm{a}$ & REC $<2$ & $1 \mathrm{~b}$ & $\mathrm{TP}>1,333$ \\
$2 \mathrm{a}$ & $2,5>\mathrm{REC}>=2$ & $1,167<\mathrm{ATP}<=1,333$ \\
$3 \mathrm{a}$ & $3>$ REC $>=2,5$ & $3 \mathrm{~b}$ & $1<\mathrm{ATP}<=1,167$ \\
$4 \mathrm{a}$ & $\mathrm{REC}>=3$ & $4 \mathrm{~b}$ & ATP $<=1$ \\
\hline
\end{tabular}

For the prediction year 2005, I examined the recommendations (ATP:s) of all 413 companies, one month at the time (4.956 data point). For each month, I employed the portfolio criterion above, and sorted each stock into the appropriate portfolio based on the analysts' consensus recommendations (ATP:s) the previous month. To get an idea on which time horizon analysts information is most valuable, I then assumed to hold each portfolio for different time periods as previously mentioned. Hence, the January 
portfolio was formed the first day in February based on recommendations and target prices set during January. It was then sold the first day of March if the holding-time was one month and the first day of May if the holding-time was three months and so on. By repeating this procedure for every stock and month I eventually obtained 4.956 observations per holding period divided between four recommendation- and ATP portfolios.

Portfolio performance evaluation. Once the formation method was established, the next step was to determine whether the trading strategies were profitable or not and thus evaluate the performance of each portfolio, 1a to $4 \mathrm{~b}$. This was conducted by using the Capital Asset Pricing Model (CAPM), which is the dominant approach in finance originally developed by Sharpe (1964). After having gained recognition in the field of finance, it is used in most studies trying to evaluate securities' performance (Barber et al., 2001, Dimson \& March, 1984); Elton et al., 1986; Stickel, 1995;). It is estimated as:

$$
R_{p t}-R_{f t}=\alpha_{p}+\beta_{p}\left(R_{m t}-R_{f t}\right)
$$

where

$\mathrm{R}_{\mathrm{pt}}=$ The return of the portfolio

$\mathrm{R}_{\mathrm{ft}}=$ The risk free rate of return (US T-Bill) with the same maturity period as the portfolio holding period

$\alpha_{\mathrm{p}}=$ The estimated CAPM intercept (Jensen's Alpha)

$\beta_{\mathrm{p}}=$ The estimated market beta (risk)

$\mathrm{R}_{\mathrm{mt}}=$ The return of the market (S\&P 500)

The purpose of this equation was to model and estimate the expected return of a particular asset or portfolio given its predetermined exposure to risk. This risk was measured with $\beta_{\mathrm{p}}$, which is an estimate of the volatility of an asset or portfolio in comparison to the market portfolio (S\&P 500). The logic behind the risk approximation was that an investor is well diversified, which implies that he or she holds the market portfolio. Therefore, the unique risk associated with each security is eliminated, and the only risk left is the security's sensitivity to market movements (Sharpe, 1964). $\beta_{p}$ was estimated as:

$$
\beta_{p}=\frac{\operatorname{Cov}\left(R_{a}, R_{m}\right)}{\operatorname{Var}\left(R_{m}\right)}
$$

where $\operatorname{Cov}\left(R_{a}, R_{m}\right)$ refers to the covariance of the return between stock $A$ and the market M (S\&P 500) whereas Var $\left(R_{m}\right)$ is the variance of the market (S\&P 500). See "Beta estimation period" in Figure 1. For each of the 413 companies, monthly returns during five years (2000-2004), or 60 data points, was compared to that of S\&P 500. The returns were calculated as logarithmic, or continuously compounded, as:

$$
R_{p, t}=\ln \left(\frac{P_{t+1}}{P_{t}}\right)
$$


Results

Figure 2 summarises the findings from the portfolio formation approach with regards to average mean returns sorted by portfolio. As evident, a reversed relationship emerged between REC and ATP portfolios. The average return was found to be the highest for the most favourable recommendations (portfolio 1a) and lowest for the least favourable recommendations (portfolio 4a), whereas the relationship was the opposite for ATP portfolios, exhibiting a better performance the lower the ATP was (portfolio 4b). Subsequently, the lower the valuation of the company was in relation to the current price (ATP), the better the stock performed, and vice versa. These findings were consistent for all time horizons (1 through 24 months), although the strength of the relationship appeared to weaken the longer the portfolio holding period was and disappeared completely after 6 months. A shortcoming with this approach was its ignorance of risk relative to return. Stocks associated with higher risk should in theory generate higher expected return for investors to consider the investment worthwhile (Markowitz, 1952). To compensate for this, Figure 3 is based on the portfolio evaluation method described in Equation 2.

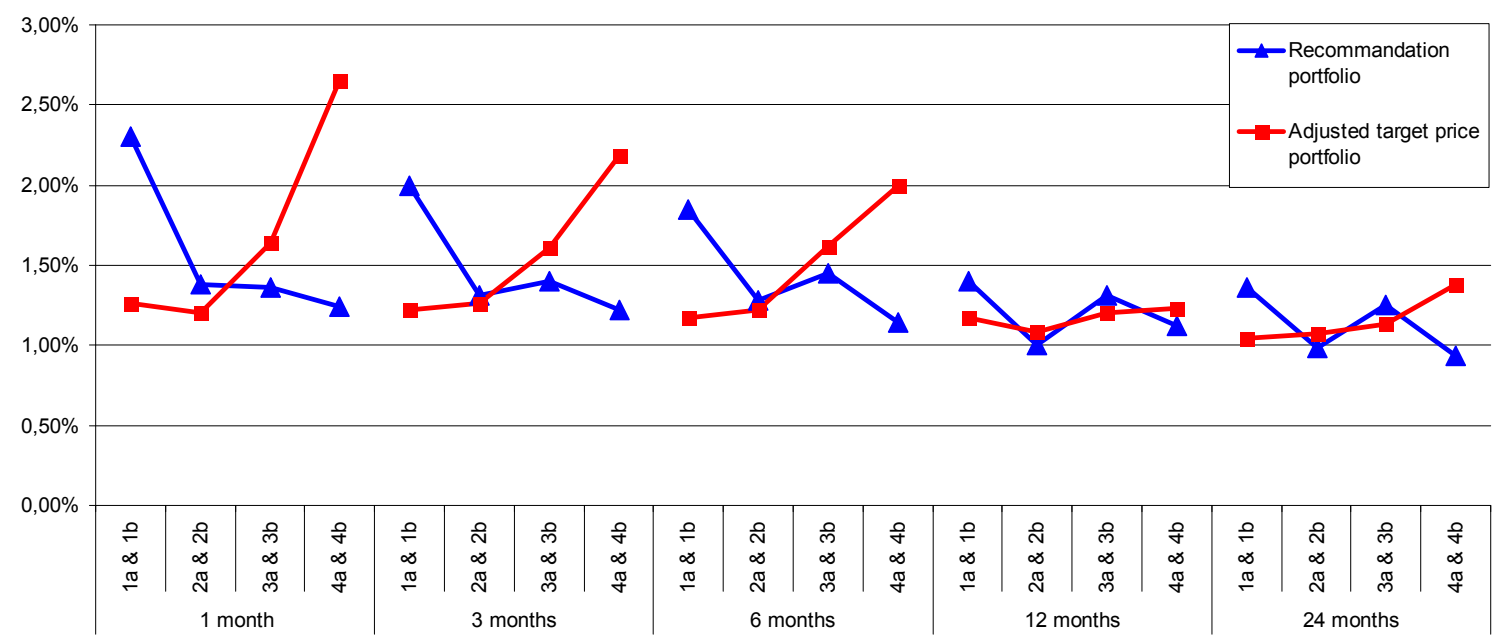

Figure 2. Average monthly portfolio return by holding period sorted by recommendation portfolios 1a $(n=563), 2 \mathrm{a}(\mathrm{n}=2317), 3 \mathrm{a}(\mathrm{n}=1501)$ and $4 \mathrm{a}(\mathrm{n}=575)$ and ATP portfolios $1 b(1148), 2 b(n=2100), 3 b(n=1409)$ and $4 b(n=299)$.

Figure 3, is calculated using abnormal returns instead of simple returns, and should therefore include more investor relevant information as it accounts for risk. The relative relationship between REC and ATP portfolios and holding periods in Figure 3 was similar that reported in Figure 2, although even more pronounced and somewhat less declining as time goes by. Indicated by the stars in Figure 3, the previously mentioned tendencies seem to be supported by the statistics, which test for if a particular portfolio's abnormal return, based on analysts' recommendations and ATP:s, was significantly higher than the expected value of zero. The highest and most significant abnormal returns, as measured by the stars in Figure 3 were reported for the one month portfolios: 1a $(p<0,001), 2 a(p<0,001), 3 a(p=0,093), 4 b(p<0,001), 3 b(p<0,001), 2 b$ $(p=0,026), 1 b(p=0,040)$, for the three month portfolios: $1 \mathrm{a}(\mathrm{p}=0,001), 2 \mathrm{a}(\mathrm{p}=0,002)$, and $4 b(p=0,030,3 b(p<0,000)$ and for the six month portfolios: 1a $(p=0,029), 2 a$ 
$(\mathrm{p}=0,047)$ and $3 \mathrm{~b}(\mathrm{p}=0,003)$. After six months, analysts' advice seemed to loose its value completely as suggested by the lack of portfolios significantly above zero.

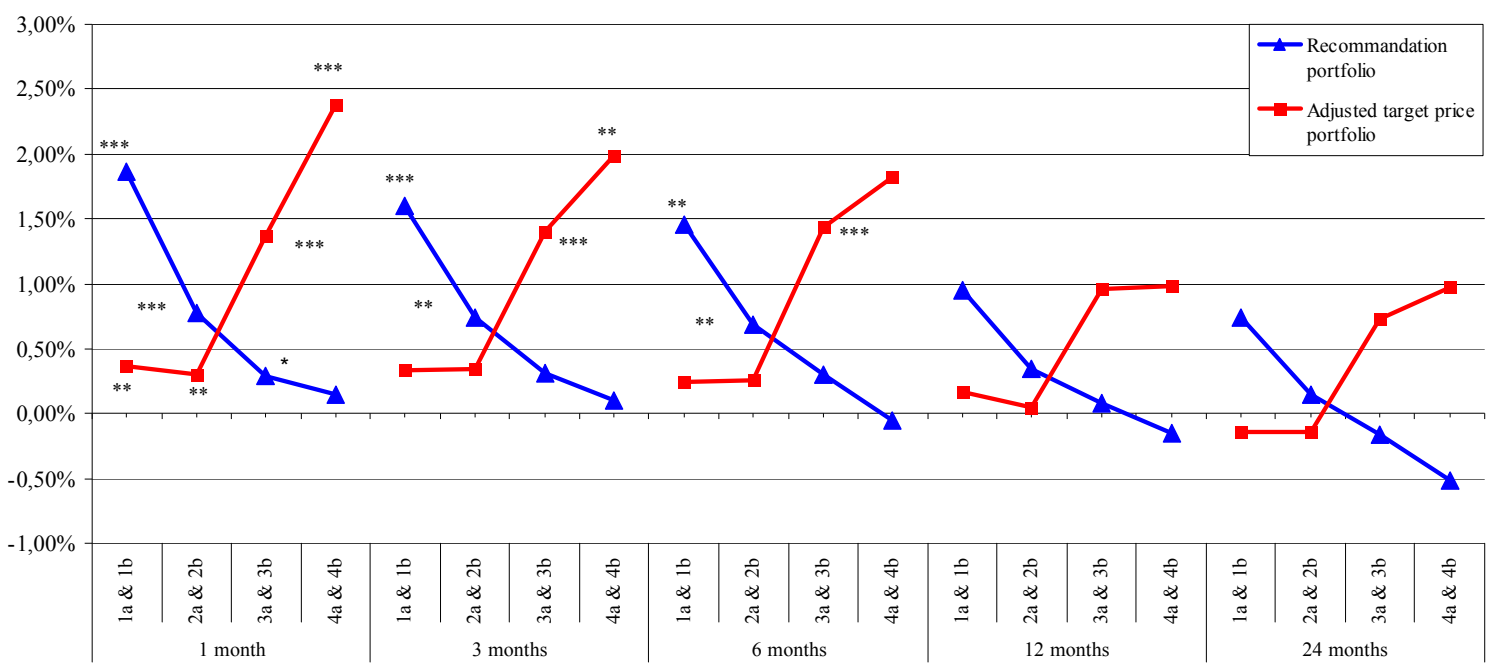

Figure 3. Average monthly portfolio abnormal return by holding period sorted by recommendation portfolios 1a $(n=563), 2 \mathrm{a}(\mathrm{n}=2317), 3 \mathrm{a}(\mathrm{n}=1501)$ and $4 \mathrm{a}(\mathrm{n}=575)$ and ATP portfolios $1 b(1148), 2 b(n=2100), 3 b(n=1409)$ and $4 b(n=299) .{ }^{*}=p<0.10, * *=p$ $<0.05$ and $* * *=\mathrm{p}<0.01$.

This linear, but reversed, relationship was further supported by Table 2, providing coefficients and p-values for regressions with abnormal returns as dependent variables and ATP and REC as independent variables. By eyeballing Table 2, it becomes clear that ATP and REC coefficients were both significantly negative for the 1,3 and 6 month period (the same period as found to be significant in Figure 3), but not for 12 and 24 months. In other words, the worse the ATP ratio was, the better the performance of the stock and the better the REC was, the better the performance of the stock. The visually observed relationships in Figure 2 and 3 thereby seemed to be supported by the regressions. It is important to note, however, that the Adjusted R-square statistics were extremely weak for all time horizons. The tested models were therefore not a particularly good predictor of future returns, but gave valuable insight about the direction of the relationship between ATP and REC and abnormal returns and whether or not it was significant. 
Table 2. Regressions with abnormal returns for the five time periods as the dependent variable and ATP and REC as independent variables. ${ }^{*}=\mathrm{p}<0.10, * *=\mathrm{p}<0.05$ and $* * *=\mathrm{p}<0.01$.

1 month $\quad 3$ months 6 months 12 months 24 months

$\begin{array}{lrrrrr}\text { Adj R-square } & 0,010 & 0,005 & 0,006 & 0,001 & 0,000 \\ & & & & & \\ \text { ATP coefficient } & -0,026 & -0,033 & -0,072 & 0,033 & 0,003 \\ \text { REC coefficient } & -0,017 & -0,019 & -0,019 & 0,020 & 0,022 \\ & & & & & \\ \text { ATP t-value } & -4,057^{* * *} & -3,192^{* * *} & -5,093^{* * *} & 1,687^{*} & 0,107 \\ \text { REC t-value } & -6,399^{* * *} & -4,314^{* * *} & -3,173^{* * *} & 2,408^{* * *} & 1,770^{*} \\ & & & & & \\ \text { ATP p-value } & 0,000 & 0,001 & 0,000 & 0,092 & 0,915 \\ \text { REC p-value } & 0,000 & 0,000 & 0,002 & 0,016 & 0,077\end{array}$

The fact that the model failed to predict abnormal returns was further investigated by Table 3, consisting of correlations between ATP and REC and abnormal returns. However, none of them appeared to be significant at any time horizon and neither was the correlation between REC and ATP $(-0,162)$. In spite of the shortcoming in predicting future abnormal returns, analysts' consensus reports do seem to have significant investment value as suggested by Figure 3. However, the rather clear negative relationship emerging from that figure was not further supported by the correlations. Instead they point out that the ATP and REC level had nothing to do with the returns.

Table 3. Correlations between the five periods' abnormal returns and ATP and REC.

1 month 3 months 6 months 12 months 24 months

$\begin{array}{llllll}\text { ATP \& Abnormal returns } & 0,007 & 0,006 & -0,056 & 0,020 & -0,015 \\ \text { REC \& Abnormal returns } & -0,035 & -0,039 & -0,034 & 0,012 & -0,026\end{array}$

\section{Discussion}

This study attempted to further the research in the field of analysts forecasting abilities by comparing and contrasting the two outputs of analysts' reports: recommendations and target prices. Focusing on Figure 2 and 3 and Table 2, consensus recommendations and target prices yielded totally different, and somewhat surprising, results. In conformity with the vast majority of the previously conducted research in the field of 
analysts' recommendations (Dimson \& March, 1984; Elton et al., 1986; Stickel, 1995), the findings indicate that those investing in accordance with the most favourable recommendations earn significant positive abnormal returns. Especially if the strategy is to buy securities with the recommendation "buy" or better, and most pronounced for trading strategies based on high frequent portfolio rebalancing. With regards to ATP portfolios, however, the tendency was the opposite. Portfolios based on stocks with a high ATP, and thus a high target price in relation to the current price, performed worse than those based on stocks with a low ATP ratio over all time horizons. The most profitable portfolios based on both recommendations and target prices earned significant positive abnormal return of about $2 \%$ which probably would be eliminated if transaction costs had been accounted for since they both required monthly rebalancing (Barber et al., 2001; Grossman \& Stiglitz, 1980). The findings with regards to the inconsistency between recommendation and ATP portfolios motivate to question what goes on when analysts produces the two measures. If they indeed produce a valuation of a company and use the output of it to generate a recommendation, then the discrepancy between the two would hardly be as high as reported in this study. In the quest for reasonable explanations for the findings, I turn to the process of making the reports, and thus the field of decision-making.

Many are the theories and theorists offering guidance in the area of human decisionmaking, only to point out that there is no simple way of describing or predicting the human mind. One of the earlier contributions, the theory of cognitive dissonance (Festinger et al., 1956), has gained recognition in the field of psychology, but gives little explanation to the behaviour observed in this study. Predicting that people strive to be consistent in acts and opinions, this theory would in accordance with common sense argue, that analysts' recommendations and ATP:s should be analogous. The same prediction was made by the theory of procedure invariance (Edwards \& Newman, 1982; Keeney \& Raiffa, 1976). However, due to the nature of the findings, these theories, named the consistency group, have to be abandoned, at least in the context of analyst decision making.

On the contrary, the obtained findings seem to fit the inconsistency group better, which represents a more critical view on analysts' consistency. One possibility is that the analysts indeed fail to construct well defined values and beliefs as suggested by Fischhoff et al. (1980), March (1978) and Shafer and Tversky (1985). This is per definition a violation of procedure invariance (Edwards \& Newman, 1982; Keeney \& Raiffa, 1976), which could owe to for example choice-matching discrepancy related to Birnbaum and Zimmermann's (1998) configural weight theory. Combined with the findings, it points out that analysts possibly highlight and weigh aspects of the information at hand differently when estimating the recommendation and target price, respectively. As a consequence, they might produce the weakly related recommendations and target prices observed in this study. Moreover, it cannot be excluded that this in turn is due to the compatibility principle (Tversky et al., 1988). If so, then analysts focus on the scale of the output (recommendation or price) and alter how they perceive the information at hand to match the response output. Subsequently, when setting the recommendation, they might overvalue the importance of aspects that are closer related to the same scale and thus might be perceived as more important for the recommendation. When setting the target price, however, they might mistakenly 
lean more on information related to price. Ultimately, this could help explain why recommendations and target prices are inconsistent. This reasoning also fits with the framing theory or preference reversals (Slovic \& Lichtenstein, 1968), which has previously been validated in business-situations (Slovic et al., 1990). Applied to the findings made in this study, it is possible that analysts perceive the information at hand differently when estimating a target price and recommendation, and therefore are receptive to this theory. This would result in loosely connected outputs in their reports which in turn would yield investment results as those found in this report. Another feasible point of departure for explaining the results is that recommendations and target prices are not set with the same temporal distance in mind (Trope \& Lieberman, 2003). It is commonly assumed that the target price has a one year perspective, but whether or not it is maintained in praxis or if the recommendation is set with the same temporal distance in mind is unknown. If so, then recommendations and target prices might be represented in more or less concrete terms, ultimately affecting their interrelation.

The above theories provide explanations for why recommendations and target prices are so weakly related but does not, however, fully account for why the relationship between the two appears to be reversed. Should analysts lack skills, as some studies have documented (Desai \& Jain, 1995), then how can the findings made in this study be explained? Supposing that analysts indeed have some abilities, then the justification of the findings needs to be sought elsewhere, such as in the very core of what goes on when they carry out their jobs. It has been reported that their concern over personal compensation occasionally damage the value of their reports (Asquith et al., 2005; Pratt, 1993). The logic behind the assumption is two-fold. Firstly, analysts are often dependant on the information they gain via the management of an assessed company. Therefore, they have to nurse the relationship with the management to qualify for this "secret" information, at the same time as their duty is to benchmark the company's future prospects "objectively". Nursing in this context is often referred to as rather being too optimistic about a company's future prospects than the opposite, as that is in the interest of the management of the assessed company. How well this balancing act is carried out ultimately echoes in the compensation the analyst receives from the company employing him or her. Secondly, analysts' proficiency, and thereby their compensation, is fairly easily evaluated with hindsight. Consequently, while striving to be objective and please the management of the assessed company, they might also use the inconsistent recommendations and target prices to justify a wide range of possible scenarios in their reports to account for the huge uncertainty predicting the future is associated with. Thereby they are rarely completely wrong but not completely right either. This mechanism has been reported by Josephs et al. (1992). They concluded that people base decisions not only on objective attributes, but also on the damage to self esteem (or compensation) that a poor decision outcome might result in. Thus, to minimize the risk of damaging self esteem, personal compensation, relations with the assessed company's management or regret, analysts do have incitement to construct their reports so that the recommendation and target price go in opposite directions. Consequently, they ensure to have covered many possible scenarios, ultimately protecting their engagement with the employing company. However, if this is the explanation, then it will remain a mystery how and why the analysts employers motivate their high compensations and their employment as such. 
The issue of analysts' recommendations and target prices seems to be a complicated one. Despite that the true nature of the discrepancy remains unknown several theories of human decision making provide valuable insight and help further the understanding of this occupational group. The most plausible reasons for the findings are summarised to the following: (1) random chance. That is, in reality there is no reversed relationship between recommendations and ATP, it just happened to look that way. (2) compatibility principle, preference reversals, configural weight theory or temporal distance theory in combination with some unknown variable which on a consistent basis drive high recommendations to be linked to low target prices and vice versa. (3) incentive to reduce regret, damage to self esteem, personal compensation or the relations with the management on the assessed company by covering a wide range of possible scenarios in the reports.

By examining financial analysts' behaviour, I intended to further the research in the financial markets from a psychological perspective. However, even though the portfolio formation method and the regression method returned results indicating that recommendations and target prices are unlike, the correlations suggested that none of the variables were related to the returns. What this indicates is unknown, but is certainly an issue for future researchers to take on. Furthermore, although measures have been taken to inflict robustness to this study, it should be kept in mind that it only contained one year of analysts reports. If the findings persist during other periods is unknown, and should be regarded as a shortcoming. In spite of its insufficiency, the present study has identified a possible anomaly in analyst' behaviour that may be understood from psychological judgment and decision making theories. Stocks with the worst future price development do seem to be the best investment. However, more research is needed to establish whether the findings remain even if other periods and methods are used.

\section{References}

Asquith, P., Mikhail, M. B., \& Au, A. S. (2005). Information content of equity analyst reports, Journal of Financial Economics, 75, 245-282.

Barber, B., Lehavy, R., McNichols, M., \& Trueman, B. (2001). Can investors profit from the prophets? Security analyst recommendations and stock returns, Journal of Finance, 56, 531-563.

Birnbaum, H. M., \& Zimmermann, M. J. (1998). Buying and selling prices of investments: configural weight model of interactions predicts violations of joint independence, Organizational Behaviour and Human Decision Processes, 74, 145-187.

Clement, M. B., \& Tse, S. Y. (2005). Financial analyst characteristics and herding behavior in forecasting, Journal of Finance, 60, 307-341.

Cowles, A. (1933). Can stock market forecasters forecast? Econometrica, 1.

Desai, H., \& Jain, P. C. (1995). An analysis of the recommendations of the "superstar" money managers at Barron's annual roundtable, Journal of Finance, 50, 1257-1273.

Dimson, E., \& March, P. (1984). An analysis of brokers' and analysts' unpublished forecasts of UK stock returns, Journal of Finance, 39, 1257-1292.

Edwards, W., \& Newman, J. R. (1982). Multiattribute evaluation. Beverly Hills, CA:Sage. 
Elton, E. J., Gruber, M. J., \& Grossman, S. (1986). Discrete expectational data and portfolio performance, Journal of Finance, 41, 699-713.

Festinger, L., Riecken, H., W., \& Schachter, S. (1956). When prophecy fails. Minneapolis: University of Minnesota Press.

Fischhoff, B., Slovic, P., \& Lichtenstein, S. (1980). Knowing what you want: measuring labile values, Cognitive processes in choice and decision behaviour, 117-141.

Grossman, S. J., Stiglitz., J. (1980). On the impossibility of informationally efficient markets, American Economic Review, 70, 393-408.

Hong, H., Kubik, J. D., \& Solomon, A. (2000). Security analysts' career concerns and herding of earnings forecasts, RAND Journal of Economics, 31, 121-144.

Josephs, R. A., Larrick, R. P., Steele, C. M., \& Nisbett, R. E. (1992). Protecting the self from the negative consequences of risky decisions, Journal of Personality and Social Psychology, 62, 26-37.

Kanne, A., \& Kreutzmann, D. (2008). Recommendations and the performance of target price changes, working paper.

Keeney, R. L., \& Raiffa, H. (1976). Decisions with multiple objectives: Preferences and value tradeoffs. New York: Wiley.

March, J. (1978). Bounded rationality, ambiguity and the rationality of choice. Bell Journal of Economics, 9, 587-608.

Markowitz, H., M. (1952). Portfolio selection, The Journal of Finance, 7, 77-91.

Pratt, T. (1993). Wall Street's four-letter word, Investment Dealers Digest, March, 18-22.

Selden, G., C. (1912). Psychology of the stock market: Human impulses lead to speculative disasters. New York: Ticker Publishing.

Shafer, G., \& Tversky, A. (1985). Language and designs for probability judgement. Cognitive Science, 9 , 309-339.

Sharpe, W., F. (1964). Capital asset prices - a theory of market equilibrium under conditions of risk, Journal of Finance, 19, 425-442.

Slovic, P., Griffin, D., \& Tversky, A. (1990). Compatibility effects in judgement and choice, Insight in decision making: Attribute to Hillil J. Einhorn, 5-27. Chicago: University of Chicago.

Slovic, P., \& Lichtenstein, S. (1968). Relative importance of probabilities and payoffs in risk-taking, Journal of Experimental Psychology Monograph, 78, 1-18.

Stickel, S., E. (1995). The anatomy of the performance of buy and sell recommendations, Financial Analysts Journal, 51, 25-39.

Trope, Y., \& Liberman, N. (2003). Temporal construal, Psychological Review, 110, 403-421.

Tversky, A., Sattah, S., \& Slovic, P. (1988). Contingent weighting in judgement and choice, Psychological Review, 95, 371-384.

Welch, I. (2000). Herding among security analysts, Journal of Financial Economics, 58, 369-396. 
Zeelenberg, M., Beattie, J., van der Pligt, J., \& de Vries, N. (1996). Consequences of regret aversion: Effects of expected feedbackon risky decision making. Organizational Behavior and Human Decision Processes, 65, 148-158. 